\title{
Evaluation of Macular and Retinal Nerve Fiber Layer Thickness in Children with Type 1 Diabetes Mellitus without Retinopathy
}

\author{
Ismail Mohd-Ilham ${ }^{1}$ Evelyn Li Min Tai ${ }^{1}$, Hussain Suhaimi ${ }^{2}$, Ismail Shatriah ${ }^{1}$ \\ ${ }^{1}$ Department of Ophthalmology and Visual Science, Hospital Universiti Sains Malaysia, Universiti Sains Malaysia School of Medical \\ Sciences, Kubang Kerian, Malaysia \\ ${ }^{2}$ Department of Pediatrics, Hospital Universiti Sains Malaysia, Universiti Sains Malaysia School of Medical Sciences, Kubang \\ Kerian, Malaysia
}

Purpose: There are limited data from Asian countries regarding retinal thickness in children with type 1 diabetes mellitus (T1DM). This study aimed to compare the macular and retinal nerve fiber layer (RNFL) parameters between diabetic children without retinopathy and non-diabetic healthy children. We also evaluated the factors associated with RNFL thickness in children with T1DM.

Methods: A comparative cross-sectional study was conducted among children with T1DM and healthy children aged 7 to 17 years old in Hospital Universiti Sains Malaysia from 2017 to 2019. Children with retinal disease or glaucoma were excluded. Macular and RNFL thicknesses were measured using spectral-domain optical coherence tomography. Demographic information, duration of diabetes, blood pressure, body mass index, visual acuity, and retinal examination findings were documented. Glycosylated hemoglobin levels, renal function, and blood lipid levels were also collected.

Results: Forty-one children with T1DM and 80 age- and sex-matched children were enrolled. Both sexes were affected. Mean duration of diabetes mellitus was 3.66 years. The mean glycated hemoglobin levels in the T1DM group was $9.99 \%$. The mean macular and RNFL thicknesses in children with T1DM were 277.56 (15.82) $\mu \mathrm{m}$ and 98.85 (12.05) $\mu \mathrm{m}$, respectively. Children with T1DM had a significantly thinner average macula, superior outer macula, nasal outer macula, mean RNFL, and inferior RNFL thickness compared to controls $(p<0.05)$. There was a significant association between nephropathy and the mean RNFL thickness.

Conclusions: Children with T1DM had significantly decreased mean macular and RNFL thicknesses. Nephropathy is associated with an increased RNFL thickness.

Key Words: Child, Macular thickness, Retinal nerve fiber layer thickness, Type 1 diabetes mellitus,

Received: November 30, 2020 Final revision: May 30, 2021 Accepted: June 3, 2021

Corresponding Author: Ismail Shatriah, MD. Department of Ophthalmology and Visual Science, Universiti Sains Malaysia School of Medical Sciences, 16150 Kubang Kerian, Kelantan, Malaysia. Tel: 60-9-767-6363, Fax: 60-9-765-3380, E-mail: shatriah@usm.my
With the increasing incidence of diabetes mellitus among pediatric populations, there has been increased interest in retinal pathologies in children with diabetes mellitus. The prevalence of retinopathy in children with diabetes ranges from $3.7 \%$ to $45.4 \%$, depending on the inclusion age and duration of diabetes [1-6]. Diabetic retinopathy has been reported in patients as young as six years of age in chil- 
dren diagnosed with type 1 diabetes mellitus (T1DM) [6].

Retinal nerve fiber layer (RNFL) thinning has been observed in eyes with early diabetic retinopathy [7]. Published literature on macular and RNFL thicknesses in children with T1DM have come from Europe, the Middle East, and China [8-14]. Based on a PubMed search, no similar reports are available from the South East Asia region. South East Asia is the region with the third highest incidence and prevalence of T1DM in children, with approximately 21,300 and 184,100 cases, respectively in 2019. These figures are surpassed by Europe and North America [15].

Our institution acts as the leading referral center in east coast states of Malaysia, with pediatric endocrine and ophthalmology services. This study aimed to compare the mean macular and RNFL thicknesses between children with T1DM and healthy controls in our tertiary center. This study also evaluated the systemic factors associated with mean RNFL thickness in children with T1DM.

\section{Materials and Methods}

This was a comparative cross-sectional hospital-based study comprised of children with and without T1DM who attended the Ophthalmology and Pediatrics Clinics of Hospital Universiti Sains Malaysia. The study was carried out from April 2017 until March 2019. Ethical approval was obtained from the Human Research Ethical Committee of the School of Medical Sciences, Universiti Sains Malaysia (USM/JEPeM/16080262). The conduct of the study was in accordance with the tenets of the Declaration of Helsinki. Written consent was obtained from the parents/guardians, and verbal assent was given by the recruited children. Children with T1DM and the control group were recruited based on a 1 to 2 ratio.

Children with T1DM who fulfilled the selection criteria were enrolled. These criteria included those aged 7 to 17 years old with a spherical equivalent between +4.00 and -4.00 diopters, an intraocular pressure equal or less than $21 \mathrm{mmHg}$, and a clear ocular media. Children who met the selection criteria but had no diabetes mellitus or other chronic medical illnesses were invited to be in the control group. The exclusion criteria for both groups were as follows: pre-existing macular diseases, congenital retinal diseases, optic disc abnormalities, optic nerve disease, a history of primary or secondary glaucoma, or a family history of glaucoma. Those with a refractive error beyond \pm 4.0 diopters or an axial length exceeding a range of 22 to $25 \mathrm{~mm}$ were also excluded.

Demographic data, including the age of onset, duration of disease, family history of diabetes, and treatment, were recorded. All children underwent a comprehensive ocular examination, including visual acuity testing, intraocular pressure measurements, slit lamp biomicroscopy, and a dilated funduscopy examination. Funduscopy photographs were taken from all children by an identified medical technician. Cycloplegic refraction was performed by an identified trained optometrist. Blood pressure readings, glycosylated hemoglobin ( $\mathrm{HbAlc}$ ) levels, renal function parameters, and lipid levels were retrieved from the patient's medical records.

Macular and RNFL thicknesses was measured with spectral-domain optical coherence tomography (OCT) using the Cirrus HD OCT (Carl Zeiss Meditec, Dublin, CA, USA). The mean macular thickness was based on the macular map protocol, using the Early Treatment Diabetic Retinopathy Study, with circles of $1 \mathrm{~mm}$ (central fovea), $3 \mathrm{~mm}$ (inner macula), and $6 \mathrm{~mm}$ (outer macula). There were nine subfield regions in the circles, including the fovea central subfield, superior inner, inferior inner, nasal inner, temporal inner, superior outer, inferior outer, nasal outer, and temporal outer of the macula. The peripapillary RNFL region was divided into four quadrants: superior, inferior, nasal, and temporal. All analyses were performed on the right eye.

To reduce study errors, the ocular examinations were performed by a single investigator and the same instruments were used. Characteristics of a quality OCT scan included the presence of uniform signal intensity, a strong reflectance signal (more than 5/10) from the RNFL, a retinal pigment epithelium layer, and a clear demarcation of both layers.

Diabetic nephropathy was defined as a urinary albumin creatinine ratio $\geq 30 \mathrm{mg} / \mathrm{g}$ on at least two consecutive morning spot urine specimens in a 3-month interval [16]. The Michigan Neuropathy Screening Instrument, which consists of a historical questionnaire to assess the presence of neuropathic symptoms and a complementary physical examination, was used to screen for peripheral neuropathy [17]. Diabetic dermopathy was diagnosed in the presence of well-demarcated, hyperpigmented, atrophic depressions, macules or papules on the anterior surface of the lower 
legs [18].

All data were collected and analyzed using the IBM SPSS Statistics ver. 24 (IBM Corp., Armonk, NY, USA). Demographic data were described in mean, standard deviation, frequency, and percentage. Normal distributions for the mean macular and RNFL thicknesses in the respective groups were tested using visual (histogram and probability graphs) and analytical methods (Kolmogorov-Smirnov and Shapiro-Wilk tests). Independent sample $t$-test was used to compare the mean macular and RNFL thicknesses between the two groups. Univariate and multivariate linear regression tests were used to determine the associations between the RNFL thickness with systemic variables, such as age of onset, duration, HbAlc levels, mean arterial pressure, insulin treatment received per day, nephropathy and hyperlipidemia. The data was adjusted for refractive status and axial length. A $p$-value less than 0.05 was considered statistically significant.

Table 1. Comparison of baseline characteristic among two groups

\begin{tabular}{lccc}
\hline Variable & T1DM & Control & $p$-value \\
\hline Current age (yr) & & & 0.784 \\
$7-12$ & $22(53.7)$ & $50(62.5)$ & \\
$13-17$ & $19(46.3)$ & $30(37.5)$ & \\
Mean \pm SD & $12.34 \pm 2.68$ & $12.23 \pm 1.92$ & \\
Age of diabetes & & & \\
onset (yr) & & & \\
Mean \pm SD & $8.73 \pm 3.38$ & - & \\
Range & $1-16$ & & \\
$\begin{array}{l}\text { Sex } \\
\text { Male }\end{array}$ & $19(46.3)$ & $38(47.5)$ & \\
$\begin{array}{l}\text { Female } \\
\text { Duration of } \\
\text { diabetes (yr) }\end{array}$ & $22(53.7)$ & $42(52.5)$ & \\
$\begin{array}{l}\text { Mean } \pm \text { SD } \\
\text { Range }\end{array}$ & $3.66 \pm 2.78$ & - & - \\
$\begin{array}{l}\text { Family history of } \\
\text { diabetes }\end{array}$ & $1-11$ & & \\
$\begin{array}{l}\text { Insulin treatment } \\
\text { (IU/kg/day) }\end{array}$ & $9(22.0)$ & - & \\
Mean \pm SD & $1.04 \pm 0.53$ & & \\
\hline
\end{tabular}

Values are presented as number (\%) unless otherwise indicated. $\mathrm{T} 1 \mathrm{DM}=$ type 1 diabetes mellitus; $\mathrm{SD}=$ standard deviation; $\mathrm{IU}=$ international unit.

*Independent $t$-test ( $p<0.05$ is significant).

\section{Results}

Forty-one children with T1DM and 80 healthy children were recruited. Both groups were age- and sex-matched. Both groups had an almost equal percentage of boys and girls. The mean age of diabetes onset was 8.73 years. The

Table 2. Clinical parameters

\begin{tabular}{|c|c|c|c|}
\hline Variable & T1DM & Control & $p$-value \\
\hline Visual acuity & & & 0.083 \\
\hline $6 / 6-6 / 9$ & $38(92.7)$ & $80(100.0)$ & \\
\hline $6 / 12-6 / 60$ & $3(7.3)$ & 0 & \\
\hline Worse than $6 / 60$ & 0 & 0 & \\
\hline $\begin{array}{l}\text { Spherical equivalent } \\
\text { (diopter) }\end{array}$ & $-0.44 \pm 1.11$ & $-0.37 \pm 0.69$ & 0.668 \\
\hline Range & $-3.50-1.00$ & $-3.13-0.88$ & \\
\hline Axial length (mm) & $22.91 \pm 0.86$ & $23.20 \pm 0.80$ & 0.712 \\
\hline Range & $21.39-24.88$ & $21.37-25.33$ & \\
\hline $\begin{array}{l}\text { Intraocular pressure } \\
(\mathrm{mmHg})\end{array}$ & $16.83 \pm 1.83$ & $16.50 \pm 3.42$ & 0.571 \\
\hline Range & $14-20$ & $11-19$ & \\
\hline Body mass index & $20.15 \pm 5.71$ & $23.21 \pm 2.66$ & $0.002^{*}$ \\
\hline \multicolumn{4}{|l|}{$\begin{array}{l}\text { Blood pressure } \\
(\mathrm{mmHg})\end{array}$} \\
\hline Systolic & $106.41 \pm 11.78$ & $112.12 \pm 9.13$ & $0.008^{*}$ \\
\hline Diastolic & $73.80 \pm 7.73$ & $69.15 \pm 8.29$ & $0.003^{*}$ \\
\hline $\begin{array}{l}\text { Mean arterial } \\
\text { pressure }\end{array}$ & $84.67 \pm 8.40$ & $83.47 \pm 7.45$ & 0.424 \\
\hline \multicolumn{4}{|l|}{ Diabetic retinopathy } \\
\hline Non-proliferative & 0 & NA & NA \\
\hline Proliferative & 0 & NA & NA \\
\hline $\begin{array}{l}\text { Diabetic } \\
\text { maculopathy }\end{array}$ & 0 & NA & NA \\
\hline Cataract & $1(2.4)$ & 0 & $0.161^{\dagger}$ \\
\hline HbA1c levels (\%) & $9.99 \pm 2.38$ & NA & NA \\
\hline Range & $5.0-14.3$ & & \\
\hline Nephropathy & $2(4.9)$ & 0 & $0.046^{* \dagger}$ \\
\hline Hyperlipidemia & $4(9.8)$ & 0 & $0.023^{* \dagger}$ \\
\hline Dermopathy & $2(4.9)$ & 0 & $0.046^{* \dagger}$ \\
\hline Neuropathy & 0 & 0 & NA \\
\hline
\end{tabular}

Values are presented as frequency (percentage) or mean \pm standard deviation unless otherwise indicated; Independent $t$-test ( $p<0.05$ is significant).

$\mathrm{T} 1 \mathrm{DM}=$ type 1 diabetes mellitus; $\mathrm{NA}=$ not available; $\mathrm{HbA} 1 \mathrm{c}=$ glycosylated hemoglobin.

"Statistically significant values; ${ }^{\dagger}$ Chi-square test $(p<0.05$ is significant). 
Table 3. Comparison of mean macular and RNFL thickness

\begin{tabular}{|c|c|c|c|c|c|}
\hline Variable & T1DM & Control & Mean diff $(95 \% \mathrm{CI})$ & t-statistic (df) & $p$-value \\
\hline \multicolumn{6}{|l|}{ Macular thickness } \\
\hline Average & $277.56 \pm 15.82$ & $282.94 \pm 11.73$ & $-5.38(-10.41$ to -0.34$)$ & $-2.11(119)$ & $0.037^{\dagger}$ \\
\hline Central & $237.71 \pm 22.96$ & $239.54 \pm 19.93$ & $-1.83(-0.82$ to 6.16$)$ & $-0.45(119)$ & 0.651 \\
\hline Inner superior & $314.46 \pm 16.76$ & $317.16 \pm 16.62$ & $-2.70(-9.04$ to 3.64$)$ & $-0.84(119)$ & 0.401 \\
\hline Inner inferior & $309.05 \pm 18.73$ & $311.99 \pm 16.39$ & $-2.94(-9.49$ to 3.61$)$ & $-0.89(119)$ & 0.376 \\
\hline Inner temporal & $303.17 \pm 17.19$ & $306.04 \pm 14.39$ & $-2.87(-8.72$ to 2.99$)$ & $-0.97(119)$ & 0.334 \\
\hline Inner nasal & $315.15 \pm 17.78$ & $320.50 \pm 15.91$ & $-5.35(-11.65$ to 0.94$)$ & $-1.68(119)$ & 0.095 \\
\hline Outer superior & $281.07 \pm 16.37$ & $287.14 \pm 14.92$ & $-6.064(-11.93$ to -0.20$)$ & $-2.05(119)$ & $0.043^{\dagger}$ \\
\hline Outer inferior & $270.41 \pm 15.86$ & $271.66 \pm 13.82$ & $-1.25(-6.78$ to 4.28$)$ & $-0.45(119)$ & 0.656 \\
\hline Outer temporal & $264.17 \pm 14.98$ & $264.24 \pm 12.13$ & $-.067(-5.07$ to 4.94$)$ & $-0.03(119)$ & 0.979 \\
\hline Outer nasal & $296.63 \pm 18.33$ & $303.54 \pm 14.24$ & $-6.903(-12.89$ to -0.92$)$ & $-0.27(119)$ & $0.024^{\dagger}$ \\
\hline \multicolumn{6}{|l|}{ RNFL thickness } \\
\hline Mean & $98.85 \pm 12.05$ & $103.41 \pm 10.92$ & $-4.56(-8.86$ to -0.26$)$ & $-2.10(119)$ & $0.045^{\dagger}$ \\
\hline Superior & $126.07 \pm 18.89$ & $129.16 \pm 20.23$ & $-3.09(-10.61$ to 4.44$)$ & $-0.81(119)$ & 0.418 \\
\hline Inferior & $129.76 \pm 22.39$ & $138.04 \pm 17.30$ & $-8.28(-15.57$ to -0.99$)$ & $-2.25(119)$ & $0.026^{\dagger}$ \\
\hline Temporal & $71.95 \pm 10.00$ & $73.78 \pm 8.55$ & $-1.82(-5.27$ to 1.62$)$ & $-1.05(119)$ & 0.297 \\
\hline Nasal & $69.34 \pm 11.16$ & $72.79 \pm 13.45$ & $-3.45(-8.29$ to 1.39$)$ & $-1.41(119)$ & 0.161 \\
\hline
\end{tabular}

Values are presented as mean \pm standard deviation.

$\mathrm{RNFL}=$ retinal nerve fiber layer; T1DM = type 1 diabetes mellitus; $\mathrm{CI}=$ confidence interval; $\mathrm{df}=$ degree of freedom.

${ }^{*}$ Independent $t$-test $\left(p<0.05\right.$ is significant); ${ }^{\dagger}$ Statistically significant values.

Table 4. Associated factors for retinal nerve fiber layer thickness in children with type 1 diabetes mellitus

\begin{tabular}{|c|c|c|c|c|c|c|}
\hline \multirow{2}{*}{ Variable } & \multicolumn{3}{|c|}{ Simple linear regression } & \multicolumn{3}{|c|}{ Multiple linear regression } \\
\hline & $\beta(95 \% \mathrm{CI})$ & t-stat & $p$-value ${ }^{*}$ & $\beta(95 \% \mathrm{CI})$ & t-stat & $p$-value ${ }^{*}$ \\
\hline $\begin{array}{l}\text { Age of diabetes } \\
\text { mellitus onset (yr) }\end{array}$ & $-0.071(-1.22$ to 1.082$)$ & -0.125 & 0.901 & & & \\
\hline $\begin{array}{l}\text { Duration of diabetes } \\
\text { mellitus (yr) }\end{array}$ & $-1.07(-2.43$ to 0.293$)$ & -1.587 & 0.121 & $-0.58(-1.89$ to 0.73$)$ & -0.892 & 0.378 \\
\hline HbA1c levels (\%) & $0.09(-1.55$ to 1.734$)$ & 0.117 & 0.908 & & - & - \\
\hline $\begin{array}{l}\text { Mean arterial pressure } \\
(\mathrm{mmHg})\end{array}$ & $-0.11(-0.58$ to 0.35$)$ & -0.500 & 0.62 & & - & - \\
\hline $\begin{array}{l}\text { Insulin treatment } \\
\text { (IU/kg/day) }\end{array}$ & $-4.75(-11.95$ to 2.45$)$ & -1.335 & 0.189 & $-4.32(-1.78$ to 3.15$)$ & -1.173 & 0.248 \\
\hline Nephropathy & 20.87 (4.30 to 37.44$)$ & 2.548 & $0.015^{\dagger}$ & 23.38 (7.00 to 39.77$)$ & 2.895 & $0.006^{\dagger}$ \\
\hline Hyperlipidemia & $10.09(-2.49$ to 22.66$)$ & 1.623 & 0.113 & $7.60(-0.87$ to 20.06$)$ & 1.236 & 0.225 \\
\hline
\end{tabular}

Adjusted for sex, refractive status, and axial length.

$\mathrm{CI}=$ confidence interval; HbAlc = glycosylated hemoglobin; IU = international unit.

${ }^{*} p<0.05$ is significant; ${ }^{\dagger}$ Statistically significant values.

mean duration of diabetes was 3.66 years. All children with T1DM received insulin treatment. These demographic parameters are summarized in Table 1.

Clinical parameters are illustrated in Table 2. Approxi- mately $93 \%$ (38 children) of the T1DM group had a best-corrected visual acuity better than $6 / 12$ (20/40). One child (2.4\%) had a mild posterior sub-capsular cataract. None of them had diabetic retinopathy, macular ede- 
ma or strabismus. The mean arterial pressure was not statistically different between the groups $(p=0.424)$. The mean HbAlc levels in the T1DM group was 9.99\%. Diabetic complications included hyperlipidemia $(9.8 \%$, four children), nephropathy (4.9\%, two children) and dermopathy ( $4.9 \%$, two children).

The comparison of the mean macular and RNFL thicknesses between the groups are shown in Table 3. The mean macular and RNFL thicknesses were significantly thinner in children with T1DM compared to the control group ( $p=$ 0.037 and $p=0.045$, respectively).

Table 4 describes the association between the age of onset of diabetes, duration of diabetes, HbAlc levels, mean arterial pressure, insulin treatment, nephropathy, and hyperlipidemia with the mean RNFL thickness in children with T1DM. There was a significant association between nephropathy and the mean RNFL thickness in these children $(p=0.006)$.

\section{Discussion}

Childhood diabetes is a risk factor for a serious chronic disorder (e.g., nephropathy, retinopathy, peripheral neuropathy, and dermopathy) $[19,20]$. Macular and RNFL thicknesses analysis may identify early changes prior to the development of diabetic-related microvasculopathy [12,21,22]. Our study demonstrated the differences in macular and RNFL thicknesses between South East Asian children with T1DM and healthy controls. Table 5 gives an overview of the mean macular thickness, the mean RNFL thickness, as well as the clinical and imaging parameters of the present study compared against the published literature in children with T1DM [8-12].

There are a few differences in macular variables from previously published studies. Akil et al. [8] reported the total macular volume in their study. El-Fayoumi et al. [9], Karti et al. [10], and Pekel et al. [11] analyzed part of the macula thickness, specifically the ganglion cell complex until the inner plexiform layer. Tekin et al. [12] and the current study measured the whole macular thickness from the inner limiting membrane until the retinal pigment epithelium. These variations are due to the different models of OCT used, as presented in Table 5 [8-12].

The mean age of children with T1DM in our study was similar to those published from Egypt and Turkey $[9,10,12]$.
The oldest age group, approximately 14 years, was reported by Karti et al. [10]. The mean duration of illness in our study was 3.66 years, which is similar to that in the study of Akil et al. [8]. Conversely, other studies have reported a longer durations of diabetes mellitus, such as 6.41 and 7.7 years $[9,12]$.

HbAlc levels reflect average blood glucose levels over a period of two to three months, and act as a proxy of diabetic control in children with T1DM. An HbAlc level of more than $8.5 \%$ is generally considered an indicator of poor glycemic control [20]. The mean HbAlc level in our patients was relatively poor $(9.99$, standard deviation 2.38$)$. Other published studies have reported ranges of mean HbAlc levels from $8.77 \%$ to $9.7 \%$ [7-10]. In contrast, the lowest mean HbAlc of $6.41 \%$ was reported by Tekin et al. [12].

None of our patients were found to have diabetic retinopathy during clinical examinations and fundus photograph reviews. Works by El-Fayoumi et al. [9], Karti et al. [10], Pekel et al. [11], and Tekin et al. [12] also reported no diabetic retinopathy changes in their patients. In contrast, Akil et al. [8] found only one patient with pre-proliferative diabetic retinopathy, evidenced by retinal microaneurysms, cotton wool spots and flame-shaped hemorrhages without neovascularization.

We observed two characteristics of macular findings in the children with T1DM without diabetic retinopathy. First, the mean average macular thickness was significantly thinner in these children than in controls. Secondly, the outer superior and outer nasal macular thicknesses were also significantly thinner in the children with T1DM. Similar findings have been reported by other researchers [1013]. This suggests that the thinning process of the macula occurs as early as the first five years of diabetes.

Our observation of reduced macular thickness in the outer quadrants may be related to the differences in cardiovascular risk factors between the two groups, such as body mass index and blood pressure. Body mass index has been associated with changes in macular thickness in the outer subfield among school-age children [23]. Hypertension has also been reported to be related to outer subfield macular thinning due to autoregulation resulting in reduced blood supply [24]. Both body mass index and blood pressure have synergistic effects on the retinal vasculature in children $[25,26]$.

In the current study, we found a significantly thinner 
Table 5. Comparison of children with type 1 diabetes mellitus from previously published studies

\begin{tabular}{|c|c|c|c|c|c|c|}
\hline & Current study & $\begin{array}{l}\text { El-Fayoumi et al. } \\
\quad(2016) \text { [9] }\end{array}$ & $\begin{array}{l}\text { Akil et al. } \\
(2016)[8]\end{array}$ & $\begin{array}{l}\text { Karti et al. } \\
(2017) \text { [10] }\end{array}$ & $\begin{array}{l}\text { Pekel et al. } \\
(2018)[11]\end{array}$ & $\begin{array}{l}\text { Tekin et al. } \\
(2018) \text { [12] }\end{array}$ \\
\hline Country & Malaysia & Egypt & USA & Turkey & Turkey & Turkey \\
\hline \multicolumn{7}{|l|}{ Patients } \\
\hline $\mathrm{DM}$ & $41(34)$ & $46(48)$ & $42(50)$ & $30(50)$ & $63(59)$ & $73(54)$ \\
\hline Control & $80(60)$ & $50(52)$ & $42(50)$ & $30(50)$ & $44(41)$ & $62(46)$ \\
\hline \multicolumn{7}{|l|}{ Age } \\
\hline $\mathrm{DM}$ & $12.34 \pm 2.68$ & $12.21 \pm 3.04$ & $13.2 \pm 3.10$ & $14.2 \pm 2.4$ & $11.9 \pm 3.4$ & $12.87 \pm 3.59$ \\
\hline Control & $12.23 \pm 1.92$ & $11.04 \pm 2.73$ & $13.26 \pm 2.60$ & $13.4 \pm 2.2$ & $12.3 \pm 2.9$ & $13.35 \pm 5.06$ \\
\hline OCT machine used & $\begin{array}{c}\text { Cirrus HD } \\
\text { (spectral } \\
\text { domain) }\end{array}$ & $\begin{array}{l}\text { RTVue Fourier } \\
\text { (spectral domain) }\end{array}$ & $\begin{array}{l}\text { Stratus } 3000 \\
\text { (time domain) }\end{array}$ & $\begin{array}{c}\text { Cirrus HD } \\
\text { (spectral } \\
\text { domain) }\end{array}$ & $\begin{array}{c}\text { Cirrus HD } \\
\text { (spectral } \\
\text { domain) }\end{array}$ & $\begin{array}{c}\text { Spectralis } \\
\text { (spectral } \\
\text { domain) }\end{array}$ \\
\hline Age of onset (yr) & $8.73 \pm 3.38$ & $4.54 \pm 2.68$ & - & - & - & - \\
\hline Duration (yr) & $3.66 \pm 2.78$ & $7.7 \pm 2.61$ & $3.6 \pm 3.1$ & $5.76 \pm 3.13$ & $4.5 \pm 2.4$ & $6.41 \pm 3.31$ \\
\hline $\mathrm{HbA1c}$ & $9.99 \pm 2.38$ & $8.77 \pm 1.73$ & $9.7 \pm 2.4$ & $9.2 \pm 2.2$ & $9.1 \pm 1.8$ & $6.33 \pm 1.26$ \\
\hline $\begin{array}{l}\text { Insulin dose } \\
\text { (IU/kg/day) }\end{array}$ & $1.04 \pm 0.53$ & $1.27 \pm 0.38$ & - & - & - & - \\
\hline Body mass index & $20.15 \pm 5.71$ & $20.27 \pm 4.69$ & - & - & $18.8 \pm 3.4$ & - \\
\hline Hyperlipidemia & $4(9.8)$ & $12(26.1)$ & - & - & - & - \\
\hline Nephropathy & $2(4.9)$ & $18(39.1)$ & - & - & - & - \\
\hline Diabetic retinopathy & 0 & 0 & $1(2.4)$ & 0 & 0 & 0 \\
\hline $\begin{array}{l}\text { Intraocular pressure } \\
(\mathrm{mmHg})\end{array}$ & $16.83 \pm 1.83$ & - & $16.7 \pm 2.9$ & $14.6 \pm 3.2$ & $17.9 \pm 2.8$ & - \\
\hline Parameters examined & $\begin{array}{l}\text { Macular and } \\
\text { RNFL }\end{array}$ & GCC and RNFL & TMV and CRT & $\begin{array}{l}\text { GC-IPL and } \\
\text { RNFL }\end{array}$ & $\begin{array}{l}\text { GC-IPL and } \\
\text { RNFL }\end{array}$ & $\begin{array}{l}\text { Macular and } \\
\text { RNFL }\end{array}$ \\
\hline Macular $(\mu \mathrm{m})$ & Macular & GCC & TMV & GC-IPL & GC-IPL & Macular \\
\hline & $237.71 \pm 22.96$ & $95.59 \pm 5.13$ & $6.68 \pm 0.64^{*}$ & $86.8 \pm 5.5$ & $86.4 \pm 6.7$ & $259.86 \pm 20.14$ \\
\hline RNFL $(\mu \mathrm{m})$ & $\begin{array}{c}\text { RNFL } \\
98.85 \pm 12.05\end{array}$ & $\begin{array}{c}\text { RNFL } \\
110.99 \pm 10.46\end{array}$ & $\begin{array}{c}\text { CRT } \\
161.31 \pm 27.84\end{array}$ & $\begin{array}{c}\text { RNFL } \\
102.0 \pm 15.5\end{array}$ & $\begin{array}{c}\text { RNFL } \\
100.5 \pm 9.10\end{array}$ & $\begin{array}{c}\text { RNFL } \\
100.27 \pm 9.38\end{array}$ \\
\hline
\end{tabular}

Values are presented as number (\%) or mean \pm standard deviation.

$\mathrm{DM}=$ diabetes mellitus; OCT $=$ optical coherence tomography; HbA1c = glycosylated hemoglobin; IU = international unit; RNFL $=$ retinal nerve fiber layer; $\mathrm{GCC}=$ ganglion cell complex; TMV $=$ total macula volume; $\mathrm{CRT}=$ central retinal thickness; $\mathrm{GC}$-IPL $=$ ganglion cell-inner plexiform layer.

$\mathrm{mm}^{3}$.

mean average RNFL and inferior RNFL in the children with T1DM compared to controls. Previously published studies have also reported a significantly thinner mean RNFL thickness in diabetics than in controls [9-10,13]. This is consistent with reports describing increased apoptosis of retinal neuronal and glial cells [27,28].

Many researchers have described that changes in the neuroretinal layer occur before clinical evidence of microvascular changes. Our findings support the hypothesis of neurodegenerative changes preceding clinically detectable diabetic retinopathy. Park et al. postulated that diabetes-associated RNFL loss might be explained by vasculopathy leading to retinal ischemia [29]. This postulation was supported by Dumitrescu et al. [30], who reported a significant association between retinal vasculopathy and structural changes of the neuro-retina in diabetic patients without diabetic retinopathy. Moreover, Sohn et al. [31] also hypothesized from animal studies that neuroretinal degeneration precedes microvasculopathy.

We found that nephropathy was associated with an increased mean RNFL thickness in children with T1DM. El-Fayoumi et al. [9] also described similar findings. Our results showed that T1DM children with nephropathy had a significantly thicker inferior RNFL thickness. This could 
be due to the presence of subclinical retinal tissue edema secondary to hypoalbuminemia, especially in dependent area. A decreased concentration of serum albumin causes an overload of body fluids and reduced intravascular oncotic pressure. This information is very crucial. T1DM children with nephropathy and increased mean RNFL thickness need to be closely monitored by their ophthalmologist and pediatric nephrologist.

In conclusion, Malaysian children with T1DM without retinopathy had a thinner macula and RNFL than children without diabetes. Nephropathy is associated with a thicker mean RNFL.

\section{Conflict of Interest}

No potential conflict of interest relevant to this article was reported.

\section{Acknowledgements}

The authors would like to acknowledge Universiti Sains Malaysia for financial support (Bridging Grant/304/ PPSP/6316157, Short Term Grant/304/PPSP/6315143), and the Unit of Biostatistics and Research Methodology, Universiti Sains Malaysia for statistical advice.

\section{References}

1. Donaghue KC, Fairchild JM, Chan A, et al. Diabetes microvascular complications in prepubertal children. $J$ Pediatr Endocrinol Metab 1997;10:579-85.

2. Kernell A, Dedorsson I, Johansson B, et al. Prevalence of diabetic retinopathy in children and adolescents with IDDM. A population-based multicentre study. Diabetologia 1997;40:307-10.

3. Olsen BS, Sjolie AK, Hougaard P, et al. The significance of the prepubertal diabetes duration for the development of retinopathy and nephropathy in patients with type 1 diabetes. J Diabetes Complications 2004;18:160-4.

4. Massin P, Erginay A, Mercat-Caudal I, et al. Prevalence of diabetic retinopathy in children and adolescents with type1 diabetes attending summer camps in France. Diabetes Metab 2007;33:284-9.
5. Agroiya P, Alrawahi AH. Pediatric diabetic retinopathy: experience of a Tertiary Hospital in Oman. Middle East Afr J Ophthalmol 2020;26:189-95.

6. Wang SY, Andrews CA, Herman WH, et al. Incidence and risk factors for developing diabetic retinopathy among youths with type 1 or type 2 diabetes throughout the United States. Ophthalmology 2017;124:424-30.

7. Dhasmana R, Sah S, Gupta N. Study of retinal nerve fibre layer thickness in patients with diabetes mellitus using fourier domain optical coherence tomography. J Clin Diagn Res 2016;10:NC05-9.

8. Akil H, Bulus AD, Andiran N, Alp MN. Ocular manifestations of type 1 diabetes mellitus in pediatric population. Indian J Ophthalmol 2016;64:654-8.

9. El-Fayoumi D, Badr Eldine NM, Esmael AF, et al. Retinal nerve fiber layer and ganglion cell complex thicknesses are reduced in children with type 1 diabetes with no evidence of vascular retinopathy. Invest Ophthalmol Vis Sci 2016; 57:5355-60.

10. Karti O, Nalbantoglu O, Abali S, et al. Retinal ganglion cell loss in children with type 1 diabetes mellitus without diabetic retinopathy. Ophthalmic Surg Lasers Imaging Retina 2017;48:473-7.

11. Pekel E, Altincik SA, Pekel G. Evaluation of optic disc, retinal nerve fiber and macular ganglion cell layers in pediatric diabetes. Int Ophthalmol 2018;38:1955-61.

12. Tekin K, Inanc M, Kurnaz E, et al. Quantitative evaluation of early retinal changes in children with type 1 diabetes mellitus without retinopathy. Clin Exp Optom 2018;101:6805.

13. Prakasam RK, Rohlig M, Fischer DC, et al. Deviation maps for understanding thickness changes of inner retinal layers in children with type 1 diabetes mellitus. Curr Eye Res 2019;44:746-52.

14. Li T, Jia Y, Wang S, et al. Retinal microvascular abnormalities in children with type 1 diabetes mellitus without visual impairment or diabetic retinopathy. Invest Ophthalmol Vis Sci 2019;60:990-8.

15. Patterson CC, Karuranga S, Salpea P, et al. Worldwide estimates of incidence, prevalence and mortality of type 1 diabetes in children and adolescents: results from the International Diabetes Federation Diabetes Atlas, 9th edition. Diabetes Res Clin Pract 2019;157:107842.

16. Huang CY, Ting WH, Lo FS, et al. Factors associated with diabetic nephropathy in children, adolescents, and adults with type 1 diabetes. J Formos Med Assoc 2017;116:924-32. 
17. Herman WH, Pop-Busui R, Braffett BH, et al. Use of the Michigan Neuropathy Screening Instrument as a measure of distal symmetrical peripheral neuropathy in type 1 diabetes: results from the Diabetes Control and Complications Trial/Epidemiology of Diabetes Interventions and Complications. Diabet Med 2012;29:937-44.

18. McCash S, Emanuel PO. Defining diabetic dermopathy. $J$ Dermatol 2011;38:988-92.

19. Daneman D. Type 1 diabetes. Lancet 2006;367:847-58.

20. Kostolanska J, Jakus V, Barak L. HbAlc and serum levels of advanced glycation and oxidation protein products in poorly and well controlled children and adolescents with type 1 diabetes mellitus. J Pediatr Endocrinol Metab 2009;22:433-42.

21. Mrugacz M, Bryl A, Zorena K. Retinal vascular endothelial cell dysfunction and neuroretinal degeneration in diabetic patients. J Clin Med 2021;10:458.

22. Ozturk H, Ozen B, Manyas H, et al. Can ocular changes be detected early in children and adolescents with type 1 diabetes mellitus without retinopathy by using optical biometry and optical coherence tomography? Int Ophthalmol 2020;40:2503-14.

23. Zhang Z, He X, Zhu J, et al. Macular measurements using optical coherence tomography in healthy Chinese school age children. Invest Ophthalmol Vis Sci 2011;52:6377-83.

24. Kong M, Kwun Y, Sung J, et al. Association between systemic hypertension and macular thickness measured by optical coherence tomography. Invest Ophthalmol Vis Sci
2015;56:2144-50.

25. Tai EL, Kueh YC, Wan Hitam WH, et al. Comparison of retinal vascular geometry in obese and non-obese children. PLoS One 2018;13:e191434.

26. Ho A, Cheung CY, Wong JS, et al. Independent and synergistic effects of high blood pressure and obesity on retinal vasculature in young children: the Hong Kong children eye study. J Am Heart Assoc 2021;10:e18485.

27. Biallosterski C, van Velthoven ME, Michels RP, et al. Decreased optical coherence tomography-measured pericentral retinal thickness in patients with diabetes mellitus type 1 with minimal diabetic retinopathy. $\mathrm{Br} J$ Ophthalmol 2007;91:1135-8.

28. Massin P, Erginay A, Haouchine B, et al. Retinal thickness in healthy and diabetic subjects measured using optical coherence tomography mapping software. Eur J Ophthalmol 2002;12:102-8.

29. Park HY, Kim IT, Park CK. Early diabetic changes in the nerve fibre layer at the macula detected by spectral domain optical coherence tomography. Br J Ophthalmol 2011; 95:1223-8.

30. Dumitrescu AG, Istrate SL, Iancu RC, et al. Retinal changes in diabetic patients without diabetic retinopathy. Rom $J$ Ophthalmol 2017;61:249-55.

31. Sohn EH, van Dijk HW, Jiao C, et al. Retinal neurodegeneration may precede microvascular changes characteristic of diabetic retinopathy in diabetes mellitus. Proc Natl Acad Sci USA 2016;113:E2655-64. 